Short Communication

\title{
Corrosion Behavior of L415 Natural Gas Pipeline in High pressure Oxygen-enriched and High salt Environment
}

\author{
Hailing Lit ${ }^{1,2}$, Hongxia Wan ${ }^{1}$, Zhiyong Liu ${ }^{1, *}$, Cuiwei Du ${ }^{1, *}$, Yuning Liu ${ }^{1}$, Xiaogang $\mathrm{Li}^{1}$ \\ ${ }^{1}$ Institute for Advanced Materials and Technology, University of Science and Technology Beijing, \\ Beijing 100083,China \\ ${ }^{2}$ College of Materials Science and Engineering, Hebei University of Engineering, Handan \\ 056038,Hebei,China \\ *E-mail: liuzhiyong7804@126.com, dcw@ustb.edu.cn
}

doi: $10.20964 / 2017.08 .51$

Received: 22 April 2017 / Accepted: 7 June 2017 / Published: 12 July 2017

\begin{abstract}
The corrosion behavior of L415 steel natural gas pipeline under high pressure oxygen-rich and highsalt environment was investigated by combining electrochemistry and immersion test with scanning electron microscope and X-ray diffraction. Results show that serious corrosion of L415 steel occurred in high-pressure oxygen-rich and high-salt environment with corrosion rate of $0.847 \mathrm{~mm}$. a-1, which belonged to serious corrosion level. The ions of the leaching liquid and the oxygen-rich environment can promote L415 steel corrosion. In terms of morphology, a thick layer of corrosion products was generated from the pitting of L415 steel surface, and some area even had a severe corrosion groove after removal of corrosion products. The corrosion of L415 steel was quite severe in high-pressure oxygen-rich and high salt environment, that the steel must be kept in inert atmosphere and swept with water having low salt concentration.
\end{abstract}

Keywords: L415 steel High pressure oxygen-enriched and high salt environment Corrosion behavior

\section{$\underline{\text { FULL TEXT }}$}

(C) 2017 The Authors. Published by ESG (www.electrochemsci.org). This article is an open access article distributed under the terms and conditions of the Creative Commons Attribution license (http://creativecommons.org/licenses/by/4.0/). 